\title{
3-N-Butylphthalide (NBP) Attenuates the Amyloid- $\beta$-Induced Inflammatory Responses in Cultured Astrocytes via the Nuclear Factor-kB Signaling Pathway
}

\author{
Hong-Mei Wanga Ting Zhanga Jian-Kang Huang Xiao-Jiang Sun
}

Department of Neurology, Shanghai Jiaotong University Affillilated Sixth People's Hospital, Shanghai,

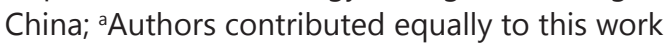

\section{Key Words}

Astrocyte $\cdot$ Amyloid $\beta$-peptide $・$ DI-3-n-butylphthalide $\bullet$ Inflammatory response $・$ Nuclear factor-kappa B

\begin{abstract}
Background/Aims: Activation of astrocytes is a common feature of Alzheimer's disease (AD). Proinflammatory molecules produced by activated astrocytes contribute to neuronal damage in AD. Moreover, dl-3-n-butylphthalide (NBP) has been reported to attenuate astroglial activation and exert neuroprotective effects in AD transgenic mice. However, the mechanism by which NBP inhibits activated astrocytes is poorly understood. Methods: In this study, the primary astrocytes were obtained from the cerebral cortices of 1-day-old Sprague-Dawley rats. The levels of GFAP, COX-2, NF- $\kappa B$, and IкB $\alpha$ were examined by Western blotting and the levels of TNF- $\alpha$ and IL- 6 were determined by ELISA. Results: NBP inhibited the amyloid- $\beta$ $(A \beta)$-induced activation of astrocytes and the up-regulation of proinflammatory molecules. Importantly, NBP markedly suppressed $A \beta$-induced IKB $\alpha$ degradation and nuclear factor$K B(N F-K B)$ translocation. Conclusion: Our results suggest that NBP attenuates $A \beta$-induced activation of astrocytes and neuroinflammation via inhibition of the NF-KB signaling pathway.
\end{abstract}

Copyright (c) 2013 S. Karger AG, Basel

\section{Introduction}

Alzheimer's disease (AD) is a progressive neurodegenerative disorder characterized by a gradual cognitive decline, and there is currently no effective treatment that stops the progression of $\mathrm{AD}$. The prominent neuropathological features in $\mathrm{AD}$ are the loss of neurons and the presence of intracellular neurofibrillary tangles and extracellular amyloid plaques. 
Amyloid $\beta$-peptide $(A \beta)$ is the major component of amyloid plaques found in the brains of $\mathrm{AD}$ patients. Amyloid deposition and the associated neuroinflammation, which contribute to neuronal loss and cognitive decline, have been proposed as pivotal events in the pathogenesis of AD. Neuroinflammation is characterized by astrocytic and microglial activation. Activated astrocytes and microglia are observed in large numbers around amyloid plaques in the brains of AD transgenic animal models and patients. In addition, a variety of proinflammatory molecules, including cyclooxygenase-2 (COX-2), interleukin-6 (IL-6), tumor necrosis factor alpha (TNF- $\alpha$ ), and inducible nitric oxide synthase (iNOS), produced by activated glial cells, are elevated in the brains of AD transgenic animal models and patients. Moreover, another proinflammatory molecule, prostaglandin E2 (PGE2), is increased in the cerebrospinal fluid (CSF) of AD patients [1]. These proinflammatory molecules, which can be released by activated astrocytes, contribute to neuronal damage and accelerate the progression of neurodegenerative disorders. Although astrocytes are involved in the neuroinflammatory process, few investigations have been conducted to understand the role of activated astrocytes in the neuroinflammatory process associated with $\mathrm{AD}$.

Nuclear factor-kappa B (NF- $\kappa \mathrm{B})$ is a family of transcription factors that are expressed in a wide variety of cells, including glial cells. NF- $\mathrm{BB}$ regulates multiple cellular pathways associated with cell differentiation, cell growth, apoptosis, and stress. NF- $\kappa \mathrm{B}$ also regulates the expression of many genes involved in the inflammatory response. The transcriptional activation of NF- $\kappa \mathrm{B}$ is tightly regulated by $\mathrm{I} \kappa \mathrm{B} \alpha$ degradation. In quiescent cells, NF- $\kappa \mathrm{B}$ remains inactive in the cytoplasm due to the formation of complexes with the inhibitory

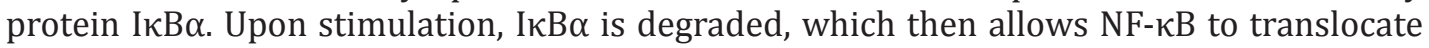
to the nucleus, bind to cognate DNA binding sites, and initiate the transcription of target proinflammatory genes, such as COX-2, TNF- $\alpha$, and interleukin-1 (IL-1). Increasing evidence suggests that upregulated NF- $\kappa B$ pathway activity is involved in the neurodegenerative process of $\mathrm{AD}$. In the brain of $\mathrm{AD}$ patients, p65 immunoreactivity is predominantly found in neurons and astrocytes in the immediate vicinity of amyloid plaques. Enhanced NF- $\mathrm{BB}$ activity in resident glial cells might be associated with the increased levels of inflammatory mediators in the brain and drive progressive neurotoxicity. Therefore, modulating glial activation and associated neuroinflammation may be beneficial in the prevention of AD.

Dl-3-n-butylphthalide (NBP), a drug commonly used to treat acute ischemic stroke in China, has been found to reduce $A \beta$-induced neurotoxicity in rat hippocampal neurons and human neuroblastoma SH-SY5Y cells [2]. A recent study found that NBP could attenuate astroglial activation and improve cognitive function in AD transgenic mice [3]. However, the mechanism by which NBP inhibits activated astrocytes has not been fully elucidated.

In our study, we determined that $A \beta$ induced the up-regulation of proinflammatory molecules (including COX-2, PGE2, TNF- $\alpha$, and IL-6) in cultured astrocytes, which can be markedly reversed by the addition of NBP. Our results demonstrated that NBP could suppress $A \beta$-induced proinflammatory molecules by inhibiting I $\kappa \alpha \alpha$ degradation and NF- $\kappa B$ activation. Taken together, our study suggested that NBP exerts anti-inflammatory effects, at least partially, by modulating the NF- $\mathrm{B}$ signaling pathway. Therefore, NBP might have considerable potential for the treatment of AD.

\section{Materials and Methods}

Antibodies and reagents

NBP was kindly provided by the Shijiazhuang Pharma Group NBP Pharmaceutical Co. Ltd. NBP was dissolved in dimethylsulfoxide (DMSO). 3-(4,5-Dimethylthiazol-2-yl)-2, Dulbecco's Modified Eagle Medium (DMEM), 5-diphenyltetrazoliumbromide (MTT), and fetal bovine serum were obtained from Invitrogen (Carlsbad, CA, USA). The antibody against glial fibrillary acidic protein (GFAP) and $A \beta_{1-42}$ peptide were from Sigma Aldrich (St. Louis, MO, USA). A $\beta_{1-42}$ peptide was dissolved in double-distilled water and incubated for 7 days at $37^{\circ} \mathrm{C}$ to form aggregated amyloid. Anti-Lamin B1 antibody was obtained from Abcam (Cambridge, MA, USA). The antibody against IкB $\alpha$ was obtained from Cell Signaling Technology (Beverly, MA, USA). 
All other antibodies were purchased from Santa Cruz Biotechnology (Santa Cruz, CA, USA). The TNF- $\alpha$ ELISA assay kit was from R\&D Systems (Minneapolis, MN, USA). The IL-6 ELISA assay kit was purchased from BD Biosciences Pharmingen (San Diego, CA, USA). The PGE2 enzyme immunoassay kit was obtained from Cayman Chemical (Ann Arbor, MI, USA). The Nuclear and Cytoplasmic Protein Extraction Kit was from the Beyotime Institute of Biotechnology (Nantong, Jiangsu, China). All other chemicals were purchased from Sigma unless otherwise indicated.

\section{Astrocyte cultures}

Primary astrocytes were obtained from the cerebral cortices of 1-day-old Sprague-Dawley rats as previously described [4]. The cells were plated in culture flasks and maintained at $37^{\circ} \mathrm{C}$ in a humidified atmosphere of $5 \% \mathrm{CO}_{2}$ and $95 \%$ air. After approximately 12 days, the confluent cultures were shaken $(200$ $\mathrm{rpm}, 4 \mathrm{~h}$ ) to separate the astrocytes from the remaining microglia and oligodendrocytes. The purity (95\%) of the astrocyte cultures was confirmed using an anti-GFAP antibody.

\section{Cell viability assays}

The viability of the astrocytes was evaluated by MTT assay as previously described [5]. In brief, the cells were treated with NBP for $24 \mathrm{~h}$. MTT $(0.5 \mathrm{mg} / \mathrm{ml})$ was added to the medium and incubated for an additional $4 \mathrm{~h}$. At the end of the incubation period, the medium with MTT was removed, and $100 \mu \mathrm{l}$ DMSO was subsequently added to each well. The absorbance at $570 \mathrm{~nm}$ was measured using a microplate reader. The cell viability was expressed as a percentage of the control culture (100\%).

\section{Western blot analyses}

To determine the levels of GFAP, COX-2, and IKB $\alpha$, total cell lysates were prepared as previously described [4]. Nuclear and cytosol fractions were prepared to assess the expression of NF- $\mathrm{kB}$ (p65). Samples containing $25 \mu \mathrm{g}$ of the protein extracts were subjected to SDS-PAGE and transferred to PVDF membranes. The membranes were blocked for 1 hour with $5 \%$ fat-free milk in TBST buffer $(150 \mathrm{mM} \mathrm{NaCl}, 50 \mathrm{mM}$ Tris-HCl pH 7.4, $0.05 \%$ Tween 20) and then incubated with the primary antibodies at $4{ }^{\circ} \mathrm{C}$ overnight. The membranes were washed and subsequently exposed to the appropriate horseradish peroxidase-conjugated secondary antibodies for $1 \mathrm{~h}$ at room temperature. After three washes in TBST, the bands were detected with enhanced chemiluminescence.

TNF- $\alpha$ assay, IL-6 assay, and PGE2 assay

The levels of TNF- $\alpha$ and IL-6 were determined by an ELISA detection kit according to the manufacturer's instructions. The level of prostaglandin E2 was measured by a PGE2 enzyme immunoassay kit (Cayman Chemicals, Ann Arbor, MI) following the manufacturer's instructions.

\section{Statistical analysis}

All data are expressed as the means \pm standard error of the mean (SEM). The statistical significance of the differences was assessed using one-way ANOVA, followed by Bonferroni's $t$ test. A value of $p<0.05$ was considered statistically significant.

\section{Results}

Effect of NBP on cellular viability of astrocytes

The primary astrocytes were obtained from the cerebral cortices of 1-day-old SpragueDawley rats. The cultured primary astrocytes were treated with NBP (0.1-100 $\mu \mathrm{M})$ for 24 $\mathrm{h}$, and the cellular viability was measured by the MTT assay. Compared with the control group, 0.1-10 $\mu \mathrm{M}$ NBP did not affect the viability of the astrocytes, whereas $100 \mu \mathrm{M}$ of NBP significantly $(\mathrm{p}<0.05)$ reduced the viability of the astrocytes (Fig. 1). Therefore, nontoxic concentrations of NBP (0.1-10 $\mu \mathrm{M})$ were used in the subsequent experiments.

NBP inhibited the levels of COX-2 and GFAP in the A $\beta$-treated astrocytes

We further investigated the levels of GFAP and COX-2 in the $A \beta_{1-42}$-treated astrocytes. The results showed that $A \beta_{1-42}$ treatment increased the levels of GFAP and COX-2 in the 
Fig. 1. Effect of NBP on the cellular viability of astrocytes. Cells were untreated or incubated with NBP (0.1-100 $\mu \mathrm{M}$ ) for $24 \mathrm{~h}$, and the cellular viability was detected by MTT. Experiments were performed in triplicate and repeated in three separate cell preparations. The data are presented as the means \pm SEM. * $\mathrm{p}<0.05$ compared with the control.
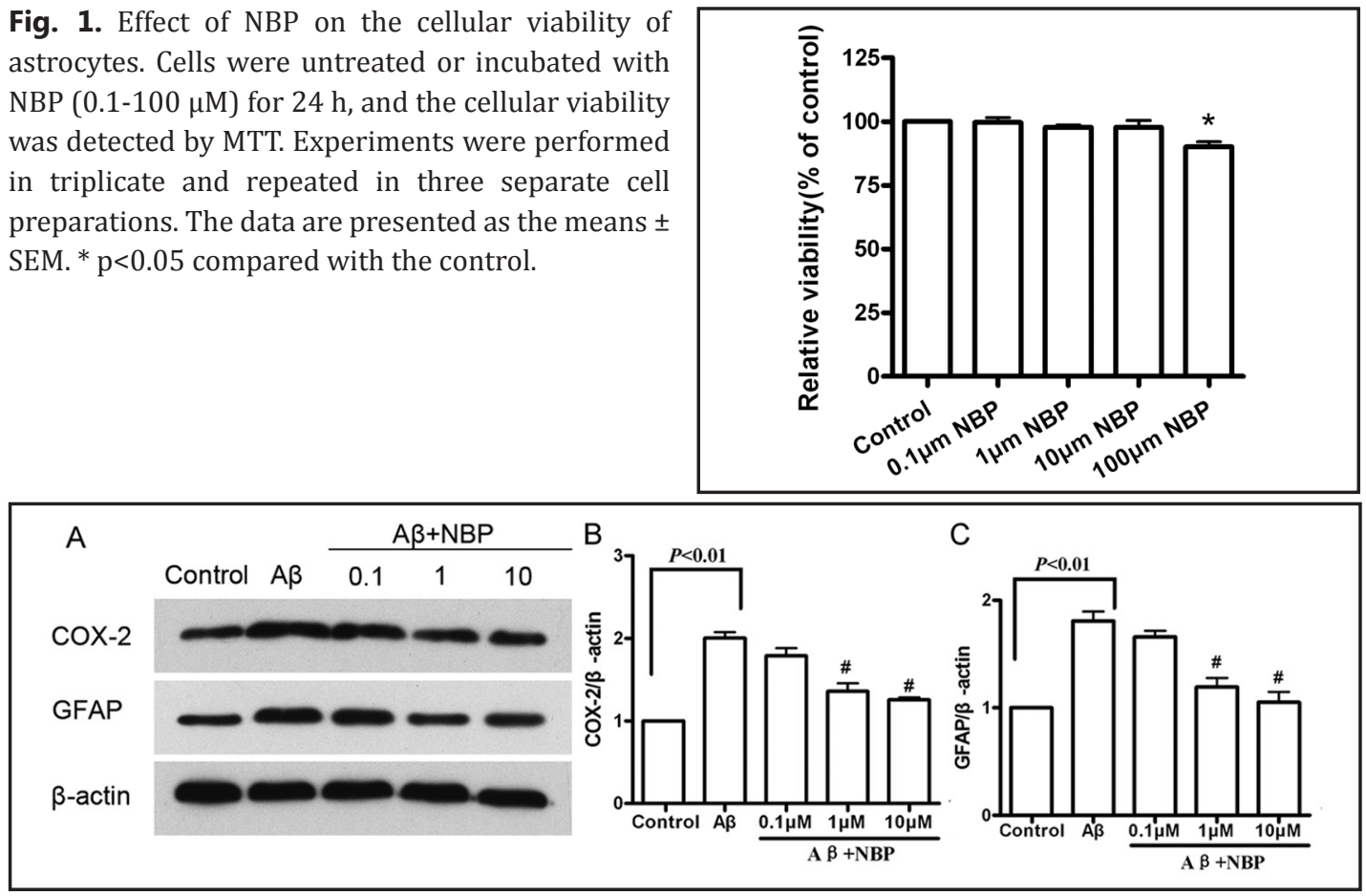

Fig. 2. Effect of NBP on the levels of GFAP and COX-2 in A $\beta$-treated astrocytes. Cells were treated with $10 \mu \mathrm{M}$ $\mathrm{A} \beta_{1-42}$ for $24 \mathrm{~h}$, or pre-incubated with NBP (0.1-10 $\left.\mu \mathrm{M}\right)$ for 30 min prior to treatment with $10 \mu \mathrm{M} \mathrm{A} \beta_{1-42}$ for $24 \mathrm{~h}$. Then the COX-2 and GFAP protein expressions were measured by western blotting. (B and C) Protein bands quantified by densitometry are expressed as the means \pm SEM. The experiments were repeated in three separate cell cultures. ${ }^{\#} \mathrm{p}<0.01$ versus $\mathrm{A} \beta$-treated group.

astrocytes. Then, we examined the effect of NBP on the levels of GFAP and COX-2 in the $\mathrm{A} \beta_{1-42}$-treated astrocytes. After the cells were treated with $10 \mu \mathrm{MA} \beta_{1-42}$ for 24 hours, or pre-incubated with NBP $(0.1-10 \mu \mathrm{M})$ for 30 min prior to treatment with $10 \mu \mathrm{M} \mathrm{A} \beta_{1-42}$ for 24 hours, western blotting was performed to test the level of GFAP and COX-2 expression. NBP $(1-10 \mu \mathrm{M})$ obviously inhibited $A \beta_{1-42}$-induced up-regulation of GFAP and COX-2 (Fig. $2)$. Nevertheless, low-dose NBP $(0.1 \mu \mathrm{M})$ failed to attenuate $A \beta_{1-42}$-induced up-regulation of GFAP and COX-2.

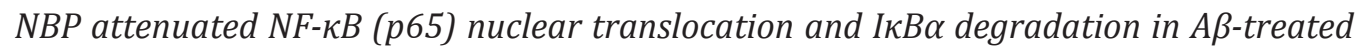
astrocytes

Our previous study found that $\mathrm{A} \beta_{25-35}$ induces the NF- $\mathrm{\kappa B}$ (p65) nuclear translocation in astrocytes, thereby increasing the production of proinflammatory molecules such as COX-2 [4]. In this study, we investigated the effect of NBP on NF- $\kappa B$ (p65) nuclear translocation in $A \beta_{1-42}$-treated astrocytes. The cells were treated with $10 \mu \mathrm{M} \mathrm{A} \beta_{1-42}$ for 24 hours or preincubated with NBP (0.1-10 $\mu \mathrm{M}$ ) for 30 min prior to treatment with $10 \mu \mathrm{M} \mathrm{A} \beta_{1-42}$ for 24 hours, and NF- $\kappa B$ (p65) protein expression was detected by western blotting. As shown in Fig. $3 A$ and $B, A \beta_{1-42}$ treatment significantly increased NF- $\mathrm{KB}$ (p65) nuclear translocation, which could be suppressed by NBP pretreatment.

It was reported that the activity of NF- $\kappa B(p 65)$ is tightly regulated by the cytoplasmic

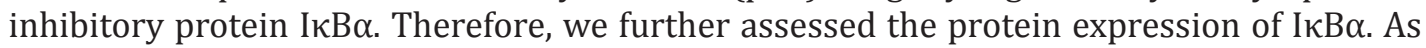
shown in Fig. 3C, $A \beta_{1-42}$ dramatically induced the degradation of I $\kappa \mathrm{B} \alpha$, which can be attenuated by pretreatment with NBP. This result was consistent with the result of NF- $\kappa B$ (p65) protein expression. NBP at concentrations ranging from 1-10 $\mu \mathrm{M}$ exhibited an inhibitory effect in a dose-dependent manner, whereas $0.1 \mu \mathrm{M}$ NBP failed to attenuate $A \beta_{1-42}$-induced NF- $\kappa B$ (p65) nuclear translocation and IкB $\alpha$ degradation. 
Fig. 3. Effect of NBP on NF- $\kappa B$ (p65) nuclear translocation and I $\mathrm{B} \alpha$ expression in $\mathrm{A} \beta$-treated astrocytes. (A) The cells were treated as described in Fig. 2A. The protein expression of NF- $\kappa \mathrm{B}$ (p65) in nuclear extracts was measured by western blotting. Lamin B1 was used as a loading control for nuclear protein. Protein bands quantified by densitometry are expressed as the means \pm SEM. The experiments were repeated in three separate cell cultures. ${ }^{*} \mathrm{p}<0.01$ versus $A \beta$-treated group. (B) The cells were treated as described in Fig. 2A. The protein expression of NF- $\kappa B$ (p65) in cytosolic extracts was measured by western blotting. $\beta$-actin was used as a loading control. Protein bands quantified by densitometry were expressed as the means \pm SEM. The experiments were repeated in

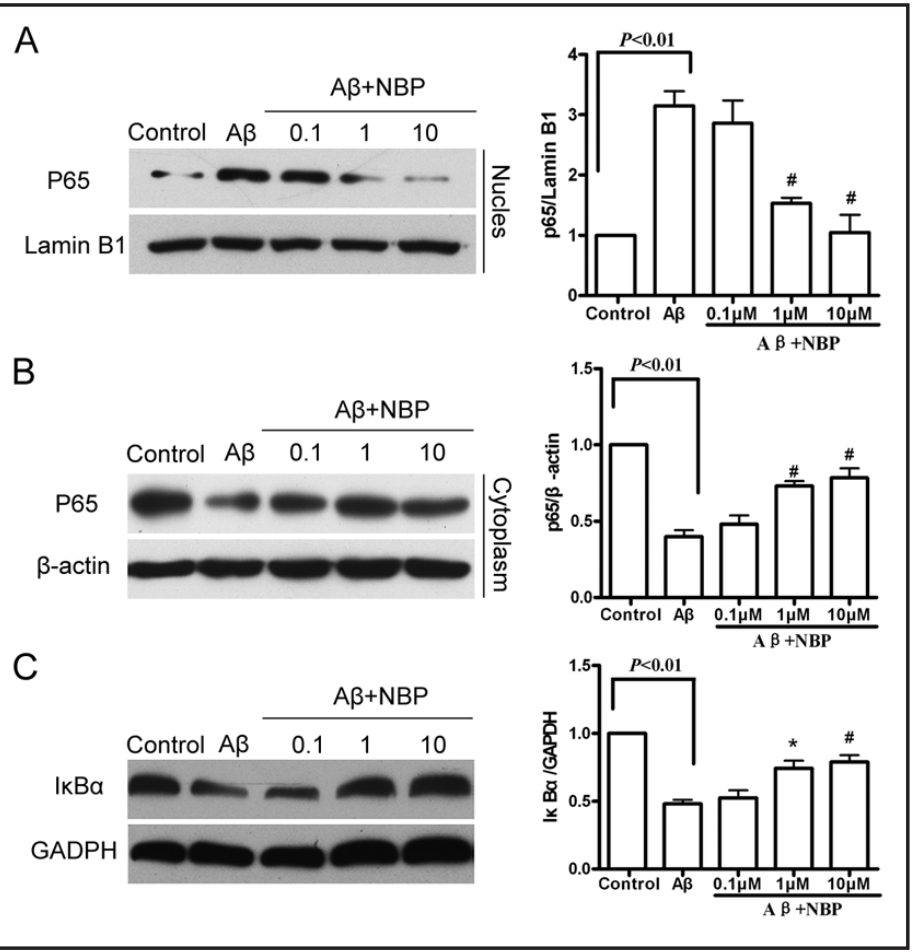
three separate cell cultures. ${ }^{*} \mathrm{p}<0.01$ versus $\mathrm{A} \beta$-treated group. (C) The cells were treated as described in Fig. 2A. The protein expression of I $\mathrm{B} \alpha$ was measured by western blotting. GAPDH was used as an internal control. The protein bands were quantified by densitometry and are expressed as the means \pm SEM. The experiments were repeated in three separate cell cultures. ${ }^{*}<0.05$ versus $A \beta$-treated group; ${ }^{\#} p<0.01$ versus A $\beta$-treated group.

\section{NBP suppressed the levels of PGE2, TNF- $\alpha$, and IL-6 in A $\beta$-treated astrocytes}

Increasing evidence suggests that PGE2 and TNF- $\alpha$ contribute to ongoing neuronal degeneration in AD. TNF- $\alpha$ can induce neuronal apoptosis in specific contexts [6] and play a role in the pathogenesis of AD [7]. Moreover, IL-6 is enhanced in AD brain and might contribute to inflammatory responses in AD. Therefore, we measured the effects of the $\mathrm{A} \beta_{1-42}$ and NBP on PGE2, TNF- $\alpha$, and IL-6 levels in astrocytes. As shown in Fig. 4A-C, $A \beta_{1-42}$ markedly increased the levels of PGE2, TNF- $\alpha$, and IL-6 in astrocytes, whereas NBP (1-10 $\mu \mathrm{M}$ ) significantly reduced $A \beta_{1-42}$-induced up-regulation of PGE2, TNF- $\alpha$, and IL-6. Consistent with the results of NF- $\kappa B$ (p65) nuclear translocation and I $\kappa \mathrm{B} \alpha$ degradation, NBP (1-10 $\mu \mathrm{M}$ ) inhibited $A \beta_{1-42}$-induced up-regulation of proinflammatory molecules, including COX2 , PGE2, TNF- $\alpha$, and IL-6 in a dose-dependent manner, whereas $0.1 \mu \mathrm{M}$ NBP failed to alter $\mathrm{A} \beta_{1-42}$-induced up-regulation of proinflammatory molecules in astrocytes.

\section{Discussion}

Astrocytes are the most numerous cells in the brain and play an important role in neuronal function. They control the extracellular $\mathrm{K}+$ homeostasis and extracellular levels of glutamate, regulate the blood-brain barrier, participate in synaptic transmission, and shape the microarchitecture of the brain [8-10]. Recently, increasing evidence suggests that activated astrocytes are involved in the pathogenesis of $\mathrm{AD}$ [11-13]. Abundant reactive astrocytes are characteristically found near amyloid plaques in AD brains [14], and the typical astrocyte marker GFAP is elevated in A $\beta P P$ transgenic mice and AD patients. Activated astrocytes can produce proinflammatory molecules and play a role in plaque formation [14]. 


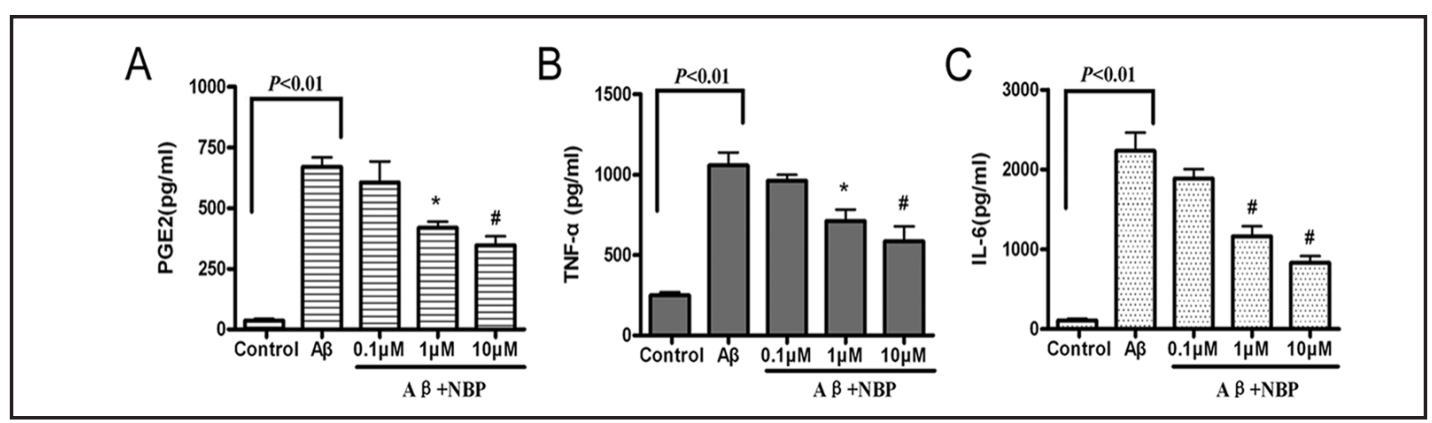

Fig. 4. Effect of NBP on the levels of PGE2, TNF- $\alpha$, and IL-6 in A $\beta$-treated astrocytes. (A) The cells were treated as described in Fig. 2A. The production of PGE2 was determined by ELISA. The experiments were performed in triplicate and repeated in three separate cell preparations. The data are presented as the means \pm SEM. ${ }^{*} p<0.05$ versus $A \beta$-treated group; ${ }^{*} p<0.01$ versus $A \beta$-treated group. (B) The cells were treated as described in Fig. 2A. The production of TNF- $\alpha$ was detected by ELISA. The experiments were performed in triplicate and repeated in three separate cell preparations. The data are presented as the means \pm SEM. ${ }^{*} \mathrm{p}<0.05$ versus $A \beta$-treated group; ${ }^{*} \mathrm{p}<0.01$ versus $A \beta$-treated group. (C) The cells were treated as described in Fig. 2. The production of IL- 6 was detected by ELISA. The experiments were performed in triplicate and repeated in three separate cell preparations. The data are presented as the means \pm SEM. ${ }^{*} p<0.01$ versus the $A \beta$-treated group.

Accumulating evidence indicates that a variety of proinflammatory cytokines and other immune neurotoxins are detected in both the cerebrospinal fluid (CSF) and the affected brain regions of AD patients [15-18]. TNF- $\alpha$, an important factor involved in the regulation of neuronal apoptosis, was found to be increased in the brains of APPswe/PS1dE9 mice. In addition, agents reducing PGE2 synthesis were shown to be neuroprotective in an animal model of AD [19], whereas administration of a TNF- $\alpha$ antagonist can improve the cognitive function of $\mathrm{AD}$ patients [20]. These studies suggest that the inflammatory response plays an important role in the pathogenesis of AD.

$\mathrm{NF}-\kappa \mathrm{B}$ is considered a primary regulator of inflammatory processes. Following cellular stimulation, NF- $\kappa$ B releases from I $\kappa B \alpha$, enters the nucleus, and promotes the transcription of its target genes. Activation of NF- $\kappa \mathrm{B}$ leads to the expression of a large variety of proinflammatory molecules that can damage and kill neurons. Previous studies have revealed that increased NF- $\kappa B$ activity can induce neuronal death and is involved in the neurodegenerative process of $\mathrm{AD}$. In the $\mathrm{AD}$ brain, NF- $\kappa \mathrm{B}$ immunoreactivity is higher in astrocytes surrounding amyloid plaques. In this study, we found that the expression of GFAP was markedly elevated in $\mathrm{A} \beta_{1-42}$-treated astrocytes. In line with the enhanced level of GFAP, proinflammatory molecules (including COX-2, PGE2, TNF- $\alpha$ and IL-6) were notably increased in astrocytes treated with $A \beta_{1-42}$. These observations suggested that $A \beta_{1-42}$ treatments induced the activation of astrocytes as well as the up-regulation of proinflammatory molecules. Moreover, $A \beta_{1-42}$ stimulation increased both I $\mathrm{B} \alpha \alpha$ degradation and NF- $\kappa \mathrm{B}$ nuclear translocation, indicating that the NF- $\kappa B$ signaling pathway participates in the $A \beta_{1-42}$-induced inflammatory response in astrocytes. Taken together, these findings suggested that the $A \beta_{1-42}$ treatment induced the degradation of I $\kappa \mathrm{B} \alpha$ and NF- $\kappa \mathrm{B}$ nuclear translocation, leading to the up-regulation of PGE2, TNF- $\alpha$, and IL- 6 in primary astrocytes. Therefore, blocking NF- $\kappa B$ activation might be an effective strategy in the treatment of AD.

NBP is a multi-target drug for the treatment of acute ischemic stroke in China. NBP exhibits protective effects against focal cerebral ischemia in animal models through the prevention of mitochondrial damage, the inhibition of neuronal apoptosis, the improvement of cerebral blood flow, and the reduction of infarct volume [21-23]. Our previous studies demonstrated that NBP could significantly inhibit caspase-3-mediated apoptosis after cerebral ischemia in diabetic rats [24]; and NBP administration could attenuate stroke-induced neuron loss and activation of astrocytes in diabetic rats [25]. However, several studies showed that NBP 
has protective effects against A $\beta$-induced neuronal injury. Peng et al. reported that NBP reduces $A \beta$-induced neurotoxicity in rat hippocampal neurons and human neuroblastoma SH-SY5Y cells [2]. It was also demonstrated that NBP could improve cognitive function and inhibit glial activation in $\mathrm{AD}$ transgenic mice [3]. However, the mechanism underlying the anti-inflammatory effect of NBP is still poorly understood. In the present study, we observed the mechanism by which NBP exerts anti-inflammatory effects on $A \beta_{1-42}$-treated astrocytes. We confirmed that NBP pretreatment not only inhibited $A \beta_{1-42}$-induced activation of astrocytes, but it also suppressed the up-regulation of COX-2, PGE2, TNF- $\alpha$, and IL- 6 triggered by $A \beta_{1-42}$. Importantly, $A \beta_{1-42}$-induced I $\kappa \mathrm{B} \alpha$ degradation and NF- $\kappa \mathrm{B}$ nuclear translocation were markedly inhibited by NBP pretreatment. These results supported the hypothesis that NBP acts as a potential NF- $\kappa B$ inhibitor. Although we can conclude that the NF- $\kappa B$ signaling pathway plays a role in the inflammatory response induced by $A \beta$, we cannot rule out the involvement of other signaling pathways that were not investigated in this study. For example, calcineurin expression is upregulated in activated astrocytes in AD model brains, and calcineurin/NFAT (Nuclear Factor of Activated T-cells) activity is elevated in postmortem human tissue at very early stages of $\mathrm{AD}$ [11]. It has been shown that calcineurin regulates cytokine production through the activation of NFAT, and the calcineurin/NFAT pathway is highly sensitive to $A \beta$ and obviously promotes cytokine production in astrocytes [11]. Furman JL et al. recently reported that selective inhibition of calcineurin/NFAT pathway in astrocytes decreased glial activation and other AD biomarkers in AD model mice [13]. In the present study, we did not achieve a total inhibition of $A \beta$-induced NF- $\kappa B$ nuclear translocation and I $\kappa \mathrm{B} \alpha$ degradation in astrocytes treated with NBP. Therefore, we cannot exclude the possibility that other pathways, such as calcineurin/NFAT, might participate in the anti-inflammatory effects of NBP. Taken together, the present study's results indicate that NBP exerts anti-inflammatory effects, at least partially, through the inhibition of NF- $\kappa B$ signaling pathways, thereby resulting in the reduction of proinflammatory molecules in $A \beta_{1-42}$-treated astrocytes. These findings suggest that NBP has considerable potential for the treatment of $\mathrm{AD}$.

\section{Acknowledgments}

This study was supported by grants from National Natural Science Foundation of China (81100953, 31100783, and 31171014).

\section{References}

$>1$ Montine TJ, Woltjer RL, Pan C, Montine KS, Zhang J: Liquid chromatography with tandem mass spectrometry-based proteomic discovery in aging and Alzheimer's disease. NeuroRx 2006;3:336-343.

- Peng Y, Xing C, Lemere CA, Chen G, Wang L, Feng Y, Wang X: L-3-n-Butylphthalide ameliorates betaamyloid-induced neuronal toxicity in cultured neuronal cells. Neurosci Lett 2008;434:224-229.

- Peng Y, Sun J, Hon S, Nylander AN, Xia W, Feng Y, Wang X, Lemere CA: L-3-n-butylphthalide improves cognitive impairment and reduces amyloid-beta in a transgenic model of Alzheimer's disease. J Neurosci 2010; 30:8180-8189.

4 Wang HM, Zhao YX, Zhang S, Liu GD, Kang WY, Tang HD, Ding JQ Chen SD: PPARgamma agonist curcumin reduces the amyloid-beta-stimulated inflammatory responses in primary astrocytes. J Alzheimers Dis 2010;20:1189-1199.

5 Wang H, Ma J, Tan Y, Wang Z, Sheng C, Chen S, Ding J: Amyloid-beta1-42 induces reactive oxygen speciesmediated autophagic cell death in U87 and SH-SY5Y cells. J Alzheimers Dis 2010;21:597-610.

6 Hsu H, Xiong J, Goeddel DV: The TNF receptor 1-associated protein TRADD signals cell death and NF-kappa B activation. Cell 1995;81:495-504. 
Wang et al.: NBP Inhibits A $\beta$-Induced Inflammation

7 Akiyama H, Barger S, Barnum S, Bradt B, Bauer J, Cole GM, Cooper NR, Eikelenboom P, Emmerling M, Fiebich BL, Finch CE, Frautschy S, Griffin WS, Hampel H, Hull M, Landreth G, Lue L, Mrak R, Mackenzie IR, McGeer PL, O'Banion MK, Pachter J, Pasinetti G, Plata-Salaman C, Rogers J, Rydel R, Shen Y, Streit W, Strohmeyer R, Tooyoma I, Van Muiswinkel FL, Veerhuis R, Walker D, Webster S, Wegrzyniak B, Wenk G, Wyss-Coray T: Inflammation and Alzheimer's disease. Neurobiol Aging 2000;21:383-421.

8 Araque A, Parpura V, Sanzgiri RP, Haydon PG: Tripartite synapses: glia, the unacknowledged partner. Trends Neurosci 1999;22:208-215.

-9 Brahmachari S, Jana A, Pahan K: Sodium benzoate, a metabolite of cinnamon and a food additive, reduces microglial and astroglial inflammatory responses. J Immunol 2009;183:5917-5927.

10 Prat A, Biernacki K, Wosik K, Antel JP: Glial cell influence on the human blood-brain barrier. Glia 2001;36:145-155.

11 Abdul HM, Sama MA, Furman JL, Mathis DM, Beckett TL, Weidner AM, Patel ES, Baig I, Murphy MP, LeVine H, 3rd, Kraner SD, Norris CM: Cognitive decline in Alzheimer's disease is associated with selective changes in calcineurin/NFAT signaling. J Neurosci 2009;29:12957-12969.

12 Mori T, Koyama N, Arendash GW, Horikoshi-Sakuraba Y, Tan J, Town T: Overexpression of human S100B exacerbates cerebral amyloidosis and gliosis in the Tg2576 mouse model of Alzheimer's disease. Glia 2009; 58:300-314.

13 Furman JL, Sama DM, Gant JC, Beckett TL, Murphy MP, Bachstetter AD, Van Eldik LJ, Norris CM: Targeting astrocytes ameliorates neurologic changes in a mouse model of Alzheimer's disease. J Neurosci 2012;32:16129-16140.

14 Nagele RG, Wegiel J, Venkataraman V, Imaki H, Wang KC: Contribution of glial cells to the development of amyloid plaques in Alzheimer's disease. Neurobiol Aging 2004;25:663-674.

15 Cacquevel M, Lebeurrier N, Cheenne S, Vivien D: Cytokines in neuroinflammation and Alzheimer's disease. Curr Drug Targets 2004;5:529-534.

16 Sun YX, Minthon L, Wallmark A, Warkentin S, Blennow K, Janciauskiene S: Inflammatory markers in matched plasma and cerebrospinal fluid from patients with Alzheimer's disease. Dement Geriatr Cogn Disord 2003;16:136-144.

17 Tarkowski E, Liljeroth AM, Minthon L, Tarkowski A, Wallin A, Blennow K: Cerebral pattern of pro- and antiinflammatory cytokines in dementias. Brain Res Bull 2003;61:255-260.

18 Strauss S, Bauer J, Ganter U, Jonas U, Berger M, Volk B: Detection of interleukin-6 and alpha 2-macroglobulin immunoreactivity in cortex and hippocampus of Alzheimer's disease patients. Lab Invest 1992;66:223-230.

19 Kotilinek LA, Westerman MA, Wang Q, Panizzon K, Lim GP, Simonyi A, Lesne S, Falinska A, Younkin LH, Younkin SG, Rowan M, Cleary J, Wallis RA, Sun GY, Cole G, Frautschy S, Anwyl R, Ashe KH: Cyclooxygenase-2 inhibition improves amyloid-beta-mediated suppression of memory and synaptic plasticity. Brain 2008;131:651-664

20 Tobinick EL, Gross H: Rapid cognitive improvement in Alzheimer's disease following perispinal etanercept administration. J Neuroinflammation 2008;5:2.

-21 Chang Q, Wang XL: Effects of chiral 3-n-butylphthalide on apoptosis induced by transient focal cerebral ischemia in rats. Acta Pharmacol Sin 2003;24:796-804.

-22 Li J, Li Y, Ogle M, Zhou X, Song M, Yu SP, Wei L: DL-3-n-butylphthalide prevents neuronal cell death after focal cerebral ischemia in mice via the JNK pathway. Brain Res 2010;1359:216-226.

23 Zhang Y, Wang L, Li J, Wang XL: 2-(1-Hydroxypentyl)-benzoate increases cerebral blood flow and reduces infarct volume in rats model of transient focal cerebral ischemia. J Pharmacol Exp Ther 2006;317:973-979.

24 Zhang T, Jia W, Sun X: 3-n-Butylphthalide (NBP) reduces apoptosis and enhances vascular endothelial growth factor (VEGF) up-regulation in diabetic rats. Neurol Res 2010;32:390-396.

25 Zhang T, Yan W, Li Q, Fu J, Liu K, Jia W, Sun X, Liu X: 3-n-Butylphthalide (NBP) attenuated neuronal autophagy and amyloid-beta expression in diabetic mice subjected to brain ischemia. Neurol Res 2011;33:396-404. 